\title{
Multidisciplinary Design Optimization of Reusable Launch Vehicles for Different Propellants and Objectives
}

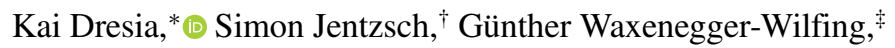 \\ Robson Dos Santos Hahn, $\underline{\S}$ and Jan Deeken- \\ DLR, German Aerospace Center, Hardthausen 74239, Germany \\ Michael Oschwald*** \\ RWTH Aachen University, Aachen 52062, Germany \\ and \\ Fabio Mota芒 \\ Federal University of ABC, São Paulo, Brazil \\ https://doi.org/10.2514/1.A34944
}

\begin{abstract}
Identifying the optimal design of a new launch vehicle is most important because design decisions made in the early development phase limit the later performance of the vehicles and determine the associated costs. Reusing the first stage via retropropulsive landing increases the complexity even more. Therefore, an optimization framework for partially reusable launch vehicles is developed, which enables multidisciplinary design studies. The framework contains suitable mass estimates of all essential subsystems and a routine to calculate the needed propellant for the ascent and landing maneuvers. For design optimization, the framework can be coupled with a genetic algorithm. The overall goal was to reveal the implications of different propellant combinations and objective functions on the optimal design of the launcher for various mission scenarios. The results show that the optimization objective influences the most suitable propellant choice and the overall launcher design, concerning staging, weight, size, and rocket engine parameters. In terms of gross lift-off weight, liquid hydrogen seems to be favorable. When optimizing for a minimum structural mass or an expendable structural mass, hydrocarbon-based solutions show better results. Finally, launch vehicles using a hydrocarbon fuel in the first stage and liquid hydrogen in the upper stage are an appealing alternative, combining the benefits of both fuels.
\end{abstract}

\begin{tabular}{|c|c|c|}
\hline & & Nomenclature \\
\hline$A$ & $=$ & rocket cross-sectional area, $\mathrm{m}$ \\
\hline$C_{d}$ & $=$ & drag coefficient \\
\hline$g_{0}$ & $=$ & standard gravity, $\mathrm{m} / \mathrm{s}^{2}$ \\
\hline$I_{\mathrm{sp}}$ & $=$ & specific impulse, $s$ \\
\hline$m$ & $=$ & mass, $\mathrm{kg}$ \\
\hline ROF & $=$ & mixture ratio \\
\hline$r$ & $=$ & stage radius, $\mathrm{m}$ \\
\hline$t_{b}$ & $=$ & burn time, $\mathrm{s}$ \\
\hline$\Delta v$ & $=$ & delta-v, m/s \\
\hline$\varepsilon$ & $=$ & structural coefficient \\
\hline
\end{tabular}

Subscripts

$c \quad=$ combustion chamber

$i=$ stage number

Received 4 September 2020; revision received 13 November 2020; accepted for publication 28 November 2020; published online Open Access 16 February 2021. Copyright (C) 2021 by DLR (German Aerospace Center). Published by the American Institute of Aeronautics and Astronautics, Inc., with permission. All requests for copying and permission to reprint should be submitted to CCC at www.copyright.com; employ the eISSN 1533-6794 to initiate your request. See also AIAA Rights and Permissions www.aiaa.org/ randp.

*Ph.D. Candidate, Institute of Space Propulsion; kai.dresia@dlr.de.

†Institute of Space Propulsion; also M.Sc. Candidate, RWTH Aachen University, Aachen 52062, Germany; simon.jentzsch@rwth-aachen.de.

"Research Scientist, Institute of Space Propulsion; guenther.waxenegger@ dlr.de.

${ }^{\S}$ Research Scientist, Institute of Space Propulsion; robson.dossantoshahn@ dlr.de.

"Head of System Analysis Group, Institute of Space Propulsion; jan.deeken@ dlr.de.

**Professor, Institute of Jet Propulsion and Turbomachinery; also Head of Rocket Propulsion Department, Institute of Space Propulsion, DLR, German Aerospace Center, Hardthausen 74239, Germany; michael.oschwald@ dlr.de. br.

$\dagger$ Professor, Aerospace Engineering Department; mota.fabio@ufabc.edu.

$\begin{array}{ll}p & =\text { propellant } \\ \mathrm{pb} & =\text { payload bay } \\ \mathrm{pl} & =\text { payload } \\ s & =\text { structure } \\ \mathrm{sl} & =\text { sea level } \\ \mathrm{vac} & =\text { vacuum } \\ 1 & =\text { first stage } \\ 2 & =\text { second stage }\end{array}$

\section{Introduction}

T HE early development phase of a new launch vehicle is critical because the selected concepts fix the majority of expected costs [1]. But, the early development phase is also challenging, as many subsystems of the vehicle are closely interlinked and influence the design choices of each other. For optimal global design, multidisciplinary design studies are necessary that consider all mission constraints and design variables at the same time. By balancing different disciplines, such as structure, propulsion, aerodynamics, or economic factors, multidisciplinary design studies can not only increase the performance of a design concept, but also reduce its expected costs.

Multidisciplinary design studies have long been used to design space launch vehicles. They have always focused on the most promising state-of-the-art technology for a powerful and cost-effective launch vehicle. During the space shuttle era, studies aimed to optimize a fully reusable winged launch vehicle, because this concept was thought to be the most economical [2-4]. After the idea of full reusability was discarded, the focus shifted to expendable launchers [ㄴ-7], demonstrating that multidisciplinary design optimization could lower the expected costs. In their study, Castellini et al. [] and Castellini [9] developed a multidisciplinary design optimization framework for expendable launch vehicles. The framework includes well-known empirical and well-validated mass and performance estimates for liquid rocket engines, and the main structural and nonstructural components of launch vehicles (e.g., propellant tanks, payload adapters, and fairings).

For some years now, economic and technical considerations have complicated the design of new launch vehicles even further. With the 
success of the partially reusable Falcon 9 of SpaceX, the international market of launch services gained a promising competitor to the traditional expendable launch vehicles. Reusing the first stage of the rocket after landing it through retro propulsion allows SpaceX to offer a significantly lower price than other launch service providers; thus, reducing costs became the driving design factor for future launch vehicles. Furthermore, with this paradigm shift from highperformance expendable launch vehicles to low-cost reusable rockets, propellant choice also needed to be reevaluated. Cryogenic liquid methane $\left(\mathrm{LCH}_{4}\right)$ is of great interest for future launch vehicles [10-13], and its properties are intensively researched [14-17]. Cryogenic $\overline{\mathrm{CH}}_{4}$ offers a potentially more economical alternative to cryogenic liquid hydrogen $\left(\mathrm{LH}_{2}\right)$ and kerosene. Because no operational launch vehicle using $\mathrm{CH}_{4}$ has been built, its impact on the overall launch vehicle configuration needs to be assessed and compared with traditional configurations. Finally, a vertical landing reusable first stage increases the complexity and the couplings between the subsystems of the launcher even more. Additional components (e.g., the landing gear) and new mission phases (e.g., the landing maneuver) need to be considered during the design phase of a new launch vehicle.

The objective function used in a multidisciplinary design study largely influences the outcome of the study. Earlier studies (compare the work of Balesdent [18] for a comprehensive overview) tried to minimize the gross lift-off weight (GLOW), the structural mass (SM), or the expected total costs, which were determined by empirical cost models $[19,20]$. Ideally, one would always want to optimize a new launch vehicle for its expected costs, but detailed cost models, especially for new technologies, are prone to errors. For (partially) reusable launch vehicles, simple mass-based objective functions might lead to nonoptimal configurations because they might not directly correlate with the expected costs. So far, however, the literature lacks a discussion about the impact of different objective functions for reusable launch configurations.

To meet the new design challenges of future launch vehicles, various multidisciplinary design studies have recently been conducted. Balesdent et al. [21] studied, among other things, the influence of technological uncertainties (e.g., new propellant combinations or reusable rocket engines) on the design process of future launch vehicles. Briese et al. [22] presented a modular multidisciplinary modeling framework for reusable launch vehicles with a particular focus on the trajectory optimization of the ascent and descent phases. On a component level, Vietze et al. [23] developed a toolbox to optimize the structure, geometry, and thermal protection system of a cryogenic launcher stage. Stappert et al. [24] reviewed different return methods and propellant combinations for a reusable first stage, taking into account preliminary design assumptions. Moroz et al. [25] even applied artificial intelligence to automatically consider reusability aspects during the preliminary design phase, such as the expected life of the turbopumps. Brevault et al. [26] optimized a multimission launcher family with a winged first stage and cryogenic $\mathrm{CH}_{4}$ as fuel in both stages.

Although some research has been carried out on multidisciplinary design optimizations for reusable launchers, no studies have been found that simultaneously include retropropulsive landing, the detailed modeling of the rocket engine, and a comparison of different propellant combinations and objective functions. However, this investigation is essential to find the optimal architecture for future cost-effective, reusable launch vehicles.

This paper aims to optimize a two-stage, partially reusable launch vehicle without making preliminary assumptions on the propellant choice, stage separation velocity, general launcher architecture (e.g., number of engines), or internal engine parameters (e.g., combustion chamber pressure). We investigate $\mathrm{LH}_{2}, \mathrm{LCH}_{4}$, and rocket propellant-1 (RP-1) as possible fuels for each stage, while liquid oxygen (LOX) is used as an oxidizer. We also examine the effects of various objective functions on the launcher design, namely GLOW, SM, and a newly defined Expendable SM (EM) defined in Eq. (7). The reusable first stage lands via retropropulsion, similar to Falcon 9 of SpaceX (downrange landing). To investigate the influence of uncertainties during predevelopment (e.g., uncertainties due to new technologies), we perform a sensitivity analysis of the engine performance and mission delta-v budget. The overall goal was to reveal the implications of different propellant combinations and objective functions on the optimal design of the launcher for various mission scenarios. As our main contributions, we

1) Develop an optimization framework for a reusable launch vehicle.

2) Include structure and propellant mass estimates for reusability aspects (e.g., landing gear and landing maneuvers).

3) Apply genetic algorithms for launch vehicle optimization.

4) Review the implications of different propellant combinations and objective functions on the design of the launcher and its engines. In this work, the focus is on gas-generator cycle engines.

The remainder of this paper is structured as follows: Sec. II describes the optimization framework for a partially reusable launch vehicle. The framework contains suitable mass and performance estimates for each subsystem of the launch vehicle, including the liquid rocket engines. Additionally, the functional principle of genetic algorithms is explained. Section III presents the mission scenario, assumptions, and results of the optimization algorithm. Section IV discusses the insights for the design of future reusable launch vehicles. Finally, Sec. $\underline{V}$ provides concluding remarks.

\section{Reusable Launch Vehicle Optimization Tool}

The reusable launch vehicle optimization tool is a framework that can design a new virtual launch vehicle based on high-level mission parameters, such as payload mass and delta-v requirements. The framework assembles an entire rocket based on these requirements and estimates the characteristics of all internal subsystems (e.g., propellant tanks) according to the expected loads. In general, the tool can choose from different propellant combinations, a variable number of stages, and multiple engines per stage. The first stage of the launch vehicle might be reusable and might land via retropropulsive landing. A general and detailed description of the underlying mass and performance calculations are given in two preceding theses $[27,28]$.

The first part of the following section describes the general program flow with a particular focus on a two-stage partially reusable launch vehicle. The second part deals with finding the optimum launch vehicle configuration for given mission requirements and constraints by using a genetic algorithm. The same approach was already used to study different engine cycles [29].

\section{A. Launch Vehicle Model}

A launch vehicle consists of its stages and the payload bay, which accommodates payload, payload adapter, avionics, and fairing. Each stage consists of its structure, including the propellant tanks, intertank, interstage, thrust frame, the means to separate itself from the upper stage or payload, its engine(s), the thrust-vector control (TVC) system, and the propellants. Figure 1 illustrates the composition of the launch vehicle.

For essential subsystems, mass estimations are implemented according to Castellini [9]. The propellant tanks are modeled as separate cylindrical tanks with spherical lids and calculated according to Barlow's formula with a safety factor of 1.5 . We further consider additional stringer and ring frame reinforcements as well as insulation, if necessary [28]. To consider the mass of the landing gear (e.g., landing legs and grid fins), the first-stage dry mass is increased by $15 \%$. This weight penalty for the landing gear was estimated by reverse-engineering Falcon 9 of SpaceX. To consider uncertainties in the mass estimates, neglected components, and neglected additional loads (e.g., due to gusts), additional mass margins are also applied. The margins are set to $10 \%$ for the upper-stage and $15 \%$ for the first-stage dry mass. Similar to Stappert et al. [30], a higher margin is applied to the first stage to reflect more substantial uncertainties about the landing gear structures and additional loads.

\section{B. Virtual Launch Vehicle Assembly}

Assembling a new virtual launch vehicle that meets all mission requirements and constraints is an iterative process. First, the launcher is built with a predefined number of engines in each stage. High-level engine performance characteristics ( $I_{\mathrm{sp}}$, thrust, and mass) are estimated with a detailed engine model based on the selected 


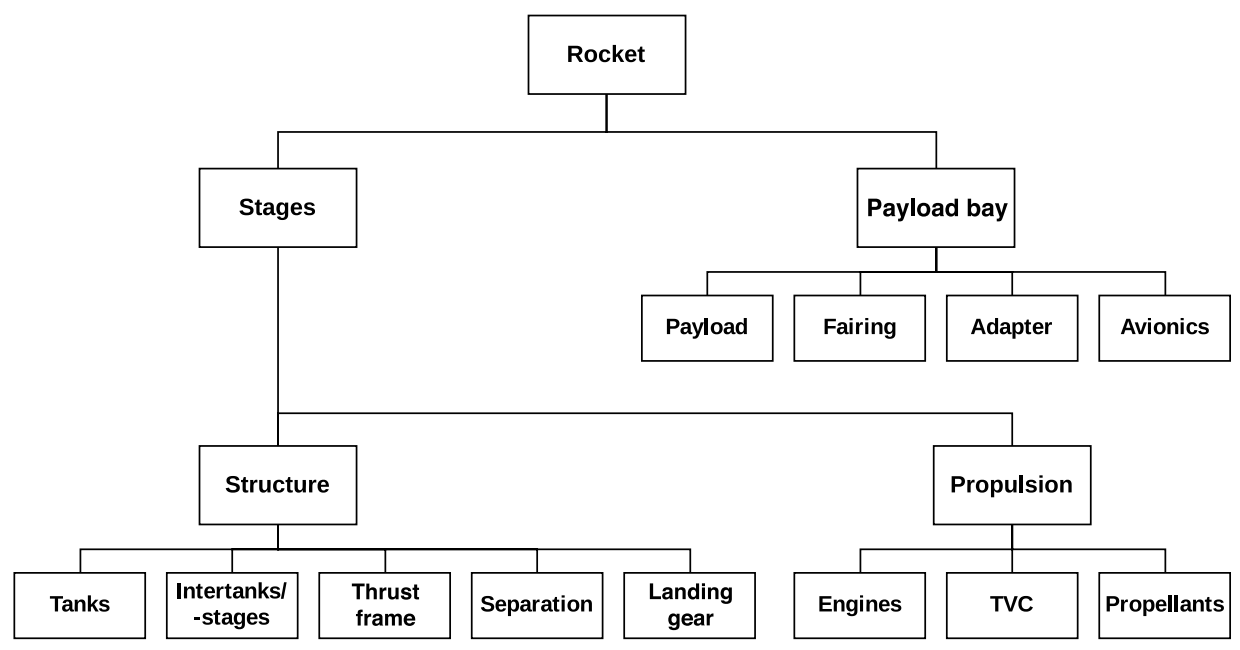

Fig. 1 Launch vehicle composition.

propellants, mixture ratios, chamber pressure, and the geometry of the engine. Secondly, the entire structure of the launcher is built, and the required propellant masses for the first and upper stages are calculated. Finally, the thrust-to-weight ratio and the minimum acceleration of each stage of the launch vehicle are checked against userdefined constraints. If the thrust-to-weight ratio of a specific stage is too small, an additional engine is added to this stage, and the design of the launch vehicle starts from the beginning. The following sections illuminate the rocket engine model and explain the propellant mass calculations in more detail, focusing on a partially reusable launch vehicle.

\section{Propulsion System}

The engine characteristics are estimated with the Chemical Equilibrium with Applications (CEA) program of NASA [31]. It can be used to obtain chemical equilibrium compositions of complex mixtures, and it can deliver theoretical rocket performance parameters. As the accuracy of the generated data varies with the combustion chamber pressure, several currently operational or historical engines were recalculated, and a correction formula was implemented based on a regression analysis of the $I_{\mathrm{sp}}$ deviations, similar to Castellini [9]. For the assumed gas-generator engines, a maximum turbine pressure ratio of 20 , turbine and pump efficiencies of $50 \%$, and a gas-generator temperature of $900 \mathrm{~K}$ are assumed. These values are used to estimate the additional propellant mass flow and the performance losses of the open engine cycle.

\section{Propellant Mass Calculations}

A reusable first stage that lands downrange through retropropulsion cannot expend all of its propellants during ascent. The propellant amount that needs to be reserved for reentry and the landing burn depends on the size and weight of the first stage. Therefore, traditional staging optimization techniques for expendable launchers are not applicable, and a different approach is necessary.

The propellant mass calculations for each stage, including the propellant mass needed for the landing of the first stage, are presented as follows. The calculations require the following input values: payload bay mass, fairing mass, specific impulse of the engines, initial values of the structural coefficients for both stages, total delta-v of the mission, as well as its allocation between the first stage $\left(\Delta v_{1 \text {,ascent }}\right)$ and the upper stage $\left(\Delta v_{2}\right)$. Furthermore, the delta-v equivalent for the reentry and landing burn $\left(\Delta v_{1, \text { landing }}\right)$ is required. The formulas for the structural coefficient $\varepsilon$, the mass ratio $m_{0} m_{f}$, and the Tsiolkovsky equation are the basis of the derived formulas for the propellant mass calculations:

$$
\begin{aligned}
\varepsilon_{i} & =\frac{m_{s, i}}{m_{s, i}+m_{p, i}}\left(\frac{m_{0}}{m_{f}}\right)_{i}=\frac{m_{s, i}+m_{p, i}+m_{\mathrm{pl}, i}}{m_{s, i}+m_{\mathrm{pl}, i}} \\
\Delta v_{i} & =g_{0} \cdot I_{\mathrm{sp}, i} \cdot \ln \left(\frac{m_{0}}{m_{f}}\right)_{i}
\end{aligned}
$$

Here, $m_{s, i}$ is the SM, $m_{p, i}$ is the propellant mass, and $m_{\mathrm{pl}, i}$ is the payload mass of a particular stage $i$. The initial and final masses of the stage are given by $m_{0}$ and $m_{f}$, while $g_{0}$ is the standard gravity. $m_{0}$ denotes the initial and $m_{f}$ the final mass of the stage. $g_{0}$ is the standard gravity. Under the simplifying assumption that the fairing is jettisoned at stage separation, the propellant mass of the upper stage can be calculated using the payload bay mass $m_{\mathrm{pb}}$ and the fairing mass $m_{\text {fairing }}$, as well as the delta-v $\Delta v_{2}$, the vacuum specific impulse

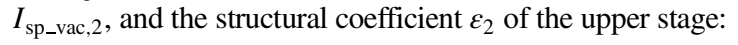

$$
m_{p, 2}=\left(m_{\mathrm{pb}}-m_{\text {fairing }}\right) \frac{1-\exp \left(\frac{\Delta v_{2}}{I_{\mathrm{sp} \_ \text {vac }, 2} \cdot g_{0}}\right)}{\frac{1}{\varepsilon_{2}-1}\left(1-\varepsilon_{2} \exp \left(\frac{\Delta v_{2}}{I_{\mathrm{sp} \_ \text {vac }, 2} \cdot g_{0}}\right)\right)}
$$

Furthermore, it is necessary to obtain an expression for the first-stage structural coefficient after stage separation $\varepsilon_{1 \text {,landing }}$ to calculate the first-stage propellant mass and its division into propellant mass for the ascent and the descent. The structural coefficient is determined with the delta-v delivered by the engines during descent $\Delta v_{1, \text { landing }}$ and the effective specific impulse of the first-stage engines $I_{\mathrm{sp}, 1} . \Delta v_{1 \text {,landing }}$ is the sum of the delta-v for the reentry burn and the landing maneuvers:

$$
\varepsilon_{1, \text { landing }}=\frac{m_{s, 1}}{m_{s, 1}+m_{p, 1, \text { landing }}}=\left(\frac{m_{0}}{m_{f}}\right)_{\text {landing }}^{-1}=\exp \left(-\frac{\Delta v_{1, \text { landing }}}{I_{\mathrm{sp}, 1} \cdot g_{0}}\right)
$$

Reverse engineering of Falcon 9 rocket of SpaceX and the application of a $5 \%$ margin led to the assumption of $\Delta v_{1 \text {,landing }}=2000 \mathrm{~m} / \mathrm{s}$ for $\Delta v_{1, \text { ascent }}=3500 \mathrm{~m} / \mathrm{s}$. For potential launch vehicles with a greater or smaller first-stage ascent delta- $\mathrm{v}, \Delta v_{1, \text { landing }}$ must be adapted accordingly. It is assumed that a higher/lower velocity at stage separation entails a longer/shorter reentry burn. Thus, the velocity of the first stage upon entering the denser parts of the atmosphere after the reentry burn is similar for all configurations. The deceleration due to drag in the denser parts of the atmosphere can be approximated with the terminal velocity:

$$
v_{1, \text { terminal }}=\sqrt{\frac{2 m g}{\rho A C_{d}}}
$$

Assuming a constant drag coefficient $C_{d}$ for all rockets, the terminal velocity scales with the square root of the projected area $A$ of the rocket and its mass $m$ for a given air density $\rho$. Table 1 shows that this coefficient is quite similar for different fuels and first-stage sizes of the optimized rockets. The landing burn takes place in a similar attitude, thus the density of the air can be assumed constant for all 
Table 1 Ratio of mass and projected area for the GLOW-, SM-, and EM-optimized rockets from Table 3

\begin{tabular}{lcc}
\hline \hline Fuel & $\Delta v_{1 . \text { ascent }}, \mathrm{km} \cdot \mathrm{s}^{-1}$ & $\sqrt{m / A}, \mathrm{t}^{1 / 2} \cdot \mathrm{m}^{-1}$ \\
\hline $\mathrm{LH}_{2}$ & $2.9 / 3.0 / 4.3$ & $1.49 / 1.48 / 1.56$ \\
$\mathrm{LCH}_{4}$ & $2.7 / 3.1 / 4.5$ & $1.45 / 1.46 / 1.57$ \\
$\mathrm{RP}-1$ & $3.0 / 3.2 / 4.4$ & $1.48 / 1.47 / 1.62$ \\
\hline \hline
\end{tabular}

launcher desings. Therefore, we can assume a similar terminal velocity at the start of the landing burn, leading to similar delta-v requirements for the landing burn.

Finally, the first-stage SM can be calculated:

$$
m_{s, 1}=m_{0,2} \frac{1-\exp \left(\frac{\Delta v_{1, \text { ascent }}}{I_{\mathrm{sp}, 1} \cdot g_{0}}\right)}{\frac{1}{\varepsilon_{1, \text { landing }}} \exp \left(\frac{\Delta v_{1, \text { ascent }}}{I_{\mathrm{sp}, 1} \cdot g_{0}}\right)-\frac{1}{\varepsilon_{1}}}
$$

where $m_{0,2}$ is the total upper-stage mass before engine ignition (including the payload bay), $\Delta v_{1, \text { ascent }}$ is the first-stage ascent delta$\mathrm{v}, I_{\mathrm{sp}, 1}$ is the effective specific impulse of the first-stage engines during ascent, $\varepsilon_{1}$ is the first-stage structural coefficient, and $\varepsilon_{1, \text { landing }}$ is the previously calculated first-stage structural coefficient after stage separation. Then, the total first-stage propellant mass, the propellant mass for first-stage landing, and the first-stage ascent propellant mass can be derived:

$$
\begin{aligned}
m_{p, 1} & =m_{s, 1} \frac{1-\varepsilon_{1}}{\varepsilon_{1}} \quad m_{p, 1, \text { landing }}=m_{s, 1} \frac{1-\varepsilon_{1, \text { landing }}}{\varepsilon_{1, \text { landing }}} \\
m_{p, 1, \text { ascent }} & =m_{p, 1}-m_{p, 1, \text { landing }}
\end{aligned}
$$

\section{Iteration and Convergence}

As the structural coefficients of the first and upper stages depend on their SMs, which are unknown at the time of propellant mass calculation, initial values need to be chosen for the first iteration. After the propellant mass of the upper stage is determined, its SM can now be calculated using the mass estimations, and a new structural coefficient is derived for the next iteration. This process is repeated until the convergence of the upper-stage structural coefficient. Subsequently, the same procedure is carried out for the first stage.

For the first stage, the effective $I_{\mathrm{sp}}$ represents an additional convergence criterion. The effective $I_{\mathrm{sp}}$ of the first stage during ascent is unknown in advance because it depends on the ascent trajectory and the particular rocket engines. For convergence, the effective $I_{\mathrm{sp}}$ is derived via a stepwise engine performance parameter calculation in a 2-D trajectory simulation until main engine cutoff. The gravity turn is simulated with a start altitude of $250 \mathrm{~m}$, a final pitch angle of $25 \mathrm{deg}$, and a constant turn rate of $0.45 \mathrm{deg} / \mathrm{s}$. With the implementation of an atmospheric model (barometric formula), the rocket position, velocity, and acceleration are determined in a 2-D space with a time step of $1 \mathrm{~s}$ until the first-stage propellant mass for the ascent is spent and the engines are cut off. This is necessary to obtain an accurate value for the effective $I_{\mathrm{sp}}$ as the ambient pressure changes during the ascent, thus influencing the expansion in the nozzle.

\section{Validation with Existing Launch Vehicle}

To validate the model of the two-stage launch vehicle with a reusable first stage, we use the Falcon 9 v1.2 Block 5 rocket as a reference vehicle because it is currently the only operational launch vehicle with this configuration. Its first stage is powered by nine Merlin engines and the upper stage by one Merlin engine featuring a larger nozzle with a higher expansion ratio. The gas-generator engines burn a LOX/RP-1 propellant mixture.

As SpaceX is a private company, not much official information is available and technical data are published very scarcely. Furthermore, the rapid evolution of the Falcon 9 rocket resulted in many modifications, thus various versions of the vehicle, making a distinction difficult. Therefore, the data used hereafter are based on unofficial estimations and cannot be expected to be $100 \%$ precise. However, the values are assumed to describe Falcon 9 sufficiently accurately.

We use the subroutines of the virtual launch vehicle assembly program to calculate the characteristics of a system similar to Falcon 9. The goal is to validate the mass estimates and the propellant calculations. We choose a $5000 \mathrm{~kg}$ payload geostationary transfer orbit (GTO) mission, which has already been demonstrated by Falcon 9 in the reusable configuration. We further fix the delta- $v$ contributions and the number of engines in the first and upper stages. Other design parameters are chosen to match the real-world Falcon 9 as closely as possible.

Table A $\underline{1}$ in the Appendix shows that we can produce a launch vehicle that is strikingly similar to the real Falcon 9 with only minor deviations. Our simplified propellant tank models result in slightly larger tanks that contain more propellant. Because of the increased weight, an engine with a slightly higher thrust has to be selected. Other high-level parameters, like the specific impulse of the engine at sea level and in vacuum, match the reference values very well.

\section{Genetic Algorithm}

The previous sections dealt with the reusable launch vehicle framework, which can design new virtual launch systems based on high-level mission requirements and design parameters. This section describes how to find the optimum set of design parameters for a given optimization goal, referred to as the objective function. Figure 2 visualizes the optimization process using a genetic algorithm. Genetic algorithms, a class of evolutionary algorithms, are numerical optimization algorithms inspired by natural selection and natural genetics [32]. Biological evolution, first formulated by Charles Darwin, builds the basis of this optimization method, which mimics the adaptive change of species through natural selection, reproduction, and the occurrence of mutations in light of the current environment [33]. Typically, a genetic algorithm uses the following components [32] : 1) a randomly generated population, representing several guesses of the solution to the problem; 2) a method for evaluating the quality of the individual solutions within the population; 3 ) a way of mixing fragments of good solutions to develop new, potentially even better solutions; and 4) a mutation operator to avoid loss of diversity, and thus local extrema within the solutions.

The advantages of such evolutionary algorithms are, among others, the conceptual simplicity, because no initial solution or gradient information is required, and their ability to find near-optimal solutions through extensive exploration. Because of their advantages, evolutionary algorithms have been extensively applied to multidisciplinary design optimizations of space transportation systems (e.g., [34,35]). Castellini and Lavagna [36] compared genetic algorithms with different state-of-the-art optimization algorithms for multi-objective global optimization. An alternative to genetic algorithms is, for example, a Bayesian-based optimization [37].

The Python package DEAP [38] provides the implementation of the genetic algorithm (called eaSimple). We use the following hyperparameters: population size of 5000; 50 generations until termination; a tournament size of the selection process of 3 ; and the four probabilities for crossover and mutation: a mating probability of 0.3 , a mutation probability 0.1 , the probability that two corresponding genes are crossed of 0.7 , and the probability that one gene mutates of 0.5 . A hyperparameter study (see [28]) verified that these hyperparameters lead to robust and converged solutions.

\section{Results of the Optimization Tool}

This section shows the results of the optimization tool for a typical mission scenario launching a payload into a low Earth orbit (LEO) and into a GTO. This study investigates how different propellant combinations and objective functions change the optimal design of the launcher. We examine multiple propellant choices for each stage (LOX/LH $\mathrm{LH}_{2}, \mathrm{LOX} / \mathrm{RP}-1$, and $\left.\mathrm{LOX} / \mathrm{CH}_{4}\right)$ and objective functions (GLOW, SM, and a newly defined EM). Furthermore, we want to 


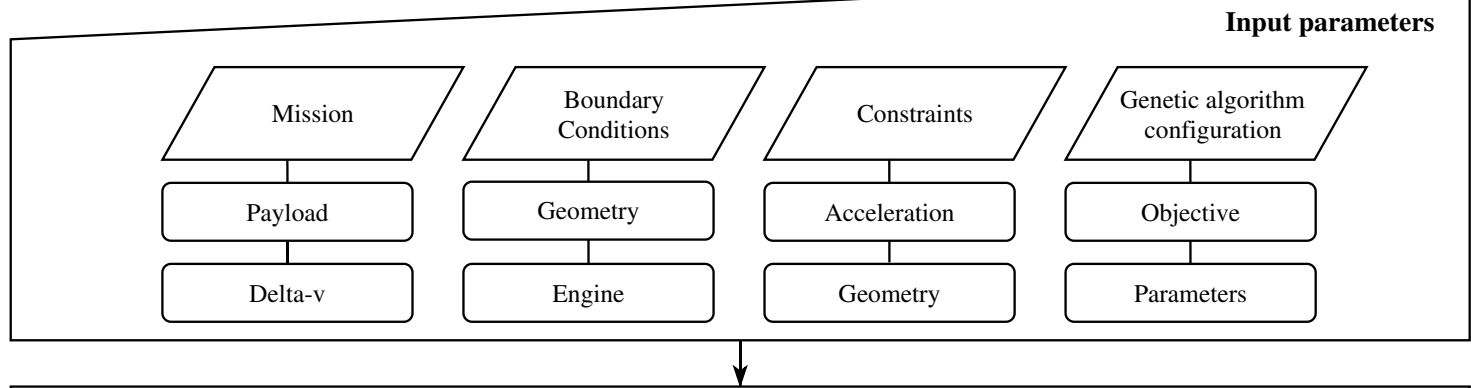

\section{Genetic Algorithm}

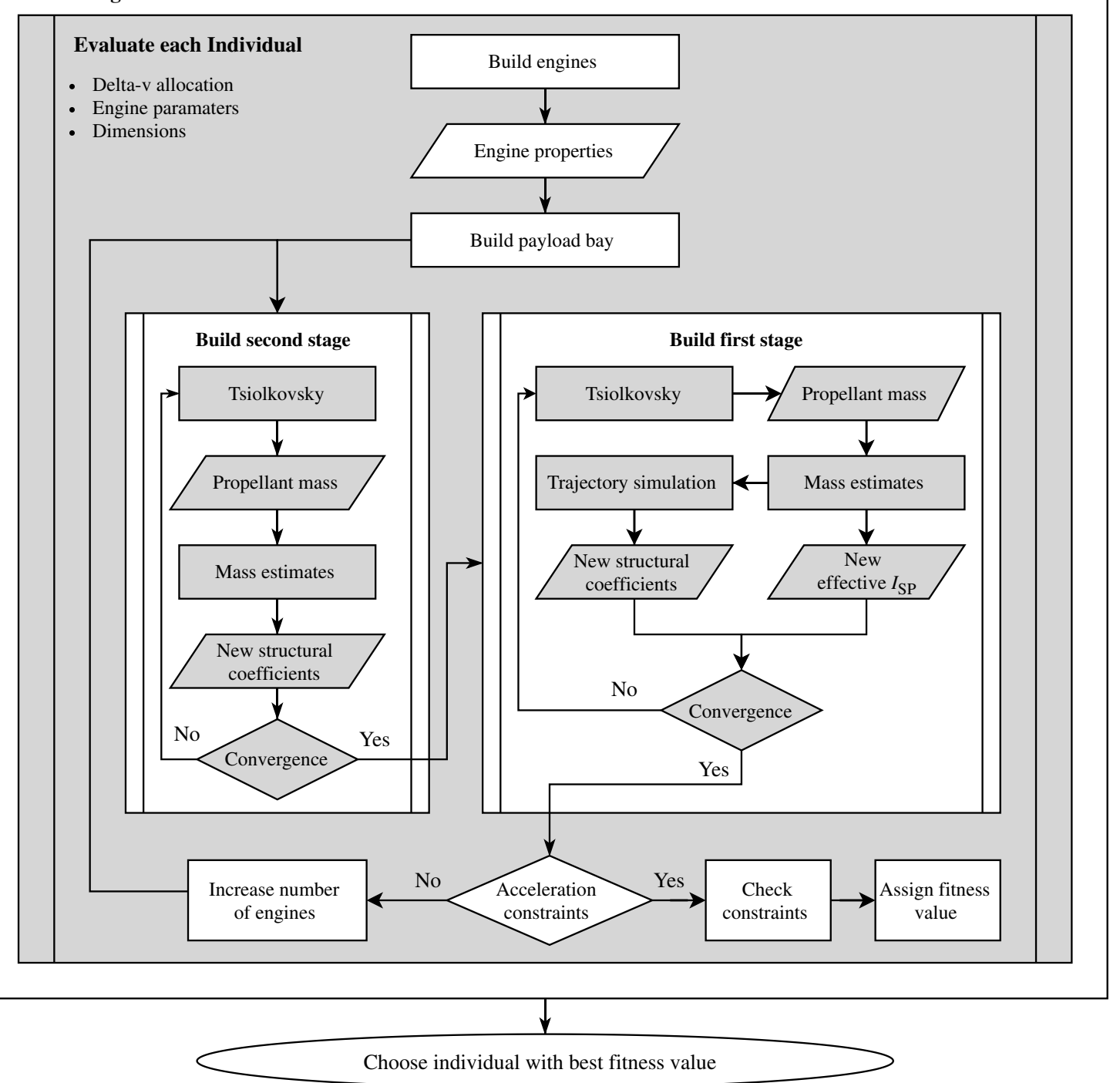

Fig. 2 Flowchart of the optimization process.

show how the mission scenario and the optimization goal influence the optimal propellant choice and the overall design of the rocket.

\section{A. Missions}

Low Earth orbit (LEO) and GTO are the most requested orbits for current and future missions. Objects in LEO circle Earth at an altitude of $200-1000 \mathrm{~km}$. Because of its proximity to the surface of Earth, this orbit is commonly used by Earth observation satellites and space stations, such as the International Space Station. To stay in orbit, objects need to travel at a speed of around $7.8 \mathrm{~km} / \mathrm{s}$. The GTO is a highly eccentric orbit, in which the payload is placed whose target orbit is a geostationary orbit. Geostationary transfer orbits (GTOs) have a perigee (point closest to Earth) of $200 \mathrm{~km}$ and an apogee (point farthest away from Earth) of $35,786 \mathrm{~km}$. When the satellite reaches the apogee, it needs to fire its engines to raise the perigee and reach the geostationary orbit.

After choosing the target orbit, the delta-v budget of the mission can be calculated. The delta-v budget or mission velocity is the sum of all flight velocity increments needed to accomplish the mission objective. It is a convenient way to describe the magnitude of the energy requirement of the space mission. The total energy requirement to put an object from the surface of Earth into orbit is the sum of the kinetic orbit energy and the potential energy needed to move the object in the gravitational field of Earth from its position on the surface to its orbital altitude. Because of gravity losses (1000-1500 m/s), aerodynamic drag (100-150 m/s), maneuvers $(15 \mathrm{~m} / \mathrm{s})$, and safety margins $(1-2 \%)$, the delta-v requirement for 
Table 2 Mission and payload requirements

\begin{tabular}{lrr}
\hline \hline Parameter & \multicolumn{1}{c}{ GTO } & \multicolumn{1}{c}{ LEO } \\
\hline$\Delta v_{\text {orbit }}, \mathrm{m} / \mathrm{s}$ & 10,430 & 8,030 \\
$\Delta v_{\text {orbit }+ \text { losses }}, \mathrm{m} / \mathrm{s}$ & 12,000 & 9,500 \\
$m_{\mathrm{pl}}, \mathrm{kg}$ & 5,000 & 15,600 \\
\hline \hline
\end{tabular}

the launch vehicle is higher than the total delta-v of the target orbit [39]. These losses are difficult to compute because drag, acceleration due to gravity, and flight path angle are unknown functions of time. Experience and data from previous missions provide a basis for conservative values of these losses. For an accurate estimation of the occurring losses, an explicit trajectory optimization would have to be performed, which is very computationally demanding. Because we want to optimize the design parameters of the launch vehicles and therefore have to evaluate many parameter combinations, we replace the detailed trajectory optimization by the mentioned conservative loss estimates. This allows us to optimize many more design parameters, but the results are potentially biased. Nevertheless, this assumption still leads to a fair comparison for launch vehicle designs with comparable thrust-to-weight ratios.

Furthermore, the rocket gains a velocity increment during launch due to the rotational speed of Earth. This effect depends on the latitude of the launch site $(460 \mathrm{~m} / \mathrm{s}$ for Kourou $)$. Delta-v requirements due to inclination changes are not considered. Table 2 summarizes the delta-v budget with and without losses, and the payload masses for the missions into a GTO of $200 \times 35,786 \mathrm{~km}$ and into a LEO of $200 \times 200 \mathrm{~km}$. The assumed losses are the same for all launch vehicles. This simplified approach should lead to good results as long as the vehicle characteristics are similar (e.g., similar thrustto-weight ratio). Note that the resulting GTO differs slightly from the Falcon 9 validation case due to the different launch site.

\section{B. Constraints}

All considered launch vehicles are partially reusable with a first stage that lands via retropropulsion and an expendable upper stage. All engines use the gas-generator cycle and one of the following propellant combinations: $\mathrm{LOX} / \mathrm{LH}_{2}, \mathrm{LOX} / \mathrm{RP}-1$, or $\mathrm{LOX} / \mathrm{LCH}_{4}$ (pure $\mathrm{CH}_{4}$ ). Furthermore, we consider mixed-propellant rockets with $\mathrm{LH}_{2}$ as fuel in the upper stage and one of the hydrocarbons in the first stage. Liquid oxygen (LOX) is always used as the oxidizer, and so it is

Table 3 Optimized launch vehicles with the same propellant combination in both stages

\begin{tabular}{|c|c|c|c|c|c|c|c|c|c|}
\hline & \multicolumn{3}{|c|}{$\mathrm{LOX} / \mathrm{LH}_{2}{ }^{\mathrm{a}}$} & \multicolumn{3}{|c|}{$\mathrm{LOX} / \mathrm{RP}-1^{\mathrm{a}}$} & \multicolumn{3}{|c|}{$\mathrm{LOX} / \mathrm{LCH}_{4}{ }^{\mathrm{a}}$} \\
\hline & $\mathrm{GLOW}^{\mathrm{b}}$ & $\mathrm{SM}^{\mathrm{b}}$ & $\mathrm{EM}^{\mathrm{b}}$ & GLOW $^{b}$ & $\mathrm{SM}^{\mathrm{b}}$ & $\mathrm{EM}^{\mathrm{b}}$ & GLOW $^{b}$ & $\mathrm{SM}^{\mathrm{b}}$ & $\mathrm{EM}^{\mathrm{b}}$ \\
\hline \multicolumn{10}{|c|}{ Mass and geometry } \\
\hline $\begin{array}{l}\text { Payload bay mass, } \mathrm{t} \\
\text { Upper stage }\end{array}$ & 7.4 & 7.4 & 7.4 & $7.3^{\circ}$ & 7.3 & 7.4 & 7.3 & 7.3 & 7.4 \\
\hline Structural mass, $\mathrm{t}$ & 9.1 & 8.6 & 5.6 & 5.9 & 5.5 & 3.8 & 7.0 & 6.1 & 4.1 \\
\hline Propellant mass, $\mathrm{t}$ & 101.1 & 95.9 & 54.6 & 143.4 & 131.3 & 74.9 & 154.0 & 127.4 & 67.9 \\
\hline Structural coefficient & 0.082 & 0.082 & 0.093 & 0.039 & 0.040 & 0.049 & 0.043 & 0.046 & 0.057 \\
\hline Diameter, $\mathrm{m}$ & 3.8 & 3.6 & 3.8 & 4.0 & 3.8 & 3.4 & 4.2 & 3.8 & 3.6 \\
\hline First stage & & & & & & & & & \\
\hline Structural mass, $\mathrm{t}$ & 27.4 & 26.8 & 38.3 & 23.0 & 22.8 & 30.0 & 22.3 & 22.7 & 30.9 \\
\hline Total propellant mass, $\mathrm{t}$ & 182.8 & 196.2 & 337.9 & 350.9 & 381.6 & 601.1 & 288.6 & 321.3 & 554.4 \\
\hline Landing propellant mass, $\mathrm{t}$ & 11.7 & 13.0 & 40.5 & 15.0 & 17.8 & 49.0 & 10.5 & 15.3 & 49.1 \\
\hline Structural coefficient & 0.130 & 0.120 & 0.102 & 0.062 & 0.056 & 0.048 & 0.072 & 0.066 & 0.053 \\
\hline Diameter, $\mathrm{m}$ & 4.4 & 4.4 & 5.0 & 4.2 & 4.2 & 4.4 & 4.2 & 4.2 & 4.6 \\
\hline \multicolumn{10}{|c|}{ Propulsion system } \\
\hline Upper stage & & & & & & & & & \\
\hline Number of engines & 1 & 1 & 1 & 1 & 1 & 1 & 1 & 1 & 1 \\
\hline$F_{\text {vac }}, \mathrm{kN}$ & 1095 & 1028 & 614 & 1439 & 1341 & 790 & 1574 & 1298 & 742 \\
\hline$I_{\text {sp_vac }}, \mathrm{s}$ & 450 & 448 & 445 & 353 & 352 & 354 & 367 & 366 & 368 \\
\hline$t_{b}, \mathrm{~s}$ & 408 & 410 & 389 & 345 & 338 & 329 & 352 & 353 & 330 \\
\hline$p_{c}$, bar & 115 & 100 & 85 & 110 & 110 & 90 & 105 & 100 & 85 \\
\hline $\mathrm{ROF}_{\text {engine }}$ & 6.5 & 6.7 & 7.0 & 2.3 & 2.4 & 2.5 & 3.1 & 3.1 & 3.2 \\
\hline $\begin{array}{l}\text { Expansion ratio } \\
\text { First stage }\end{array}$ & 200 & 200 & 200 & 200 & 190 & 195 & 195 & 180 & 200 \\
\hline Number of engines & 5 & 5 & 5 & 6 & 5 & 6 & 5 & 5 & 5 \\
\hline$F_{\text {vac,tot }}, \mathrm{kN}$ & 4896 & 4905 & 6407 & 7717 & 7773 & 10488 & 7032 & 6958 & 9956 \\
\hline$I_{\text {sp_vac }}, \mathrm{s}$ & 418 & 399 & 409 & 319 & 307 & 315 & 334 & 327 & 335 \\
\hline$I_{\mathrm{sp \_ sl}}, \mathrm{s}$ & 369 & 362 & 361 & 281 & 286 & 283 & 292 & 298 & 290 \\
\hline$t_{b}, \mathrm{~s}$ & 153 & 157 & 212 & 143 & 148 & 177 & 134 & 148 & 183 \\
\hline$p_{c}$, bar & 115 & 115 & 135 & 110 & 120 & 130 & 105 & 120 & 135 \\
\hline $\mathrm{ROF}_{\text {engine }}$ & 5.5 & 6.7 & 6.4 & 2.1 & 2.0 & 2.0 & 2.8 & 2.8 & 2.8 \\
\hline Expansion ratio & 25 & 20 & 30 & 25 & 15 & 25 & 25 & 20 & 35 \\
\hline Thrust/weight & 1.49 & 1.46 & 1.44 & 1.45 & 1.42 & 1.46 & 1.47 & 1.43 & 1.50 \\
\hline Delta-v allocation, $\mathrm{km} / \mathrm{s}$ & $2.9 / 9.1$ & $3.0 / 9.0$ & $4.3 / 7.7$ & $\begin{array}{r}\text { Total } \\
3.0 / 9.0\end{array}$ & $3.2 / 8.8$ & $4.4 / 7.6$ & $2.7 / 9.3$ & $3.1 / 8.9$ & $4.5 / 7.5$ \\
\hline Length, $\mathrm{m}$ & 87.8 & 86.8 & 87.3 & 65.5 & 66.9 & 75.4 & 70.3 & 72.0 & 79.8 \\
\hline Total structural mass, $\mathrm{t}$ & 36.4 & 35.4 & 43.9 & 28.9 & 28.3 & 33.8 & 29.3 & 28.8 & 35.0 \\
\hline Expendable mass, $\mathrm{t}$ & 10.5 & 9.9 & 7.5 & 7.1 & 6.6 & 5.3 & 8.1 & 7.2 & 5.6 \\
\hline GLOW, t & 327.8 & 334.9 & 443.9 & 530.6 & 548.5 & 717.2 & 479.2 & 484.9 & 664.7 \\
\hline
\end{tabular}

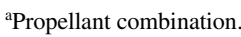

${ }^{\mathrm{b}}$ Objective function. 
Table 4 Optimized launch vehicles with different propellant combinations in each stage

\begin{tabular}{|c|c|c|c|c|c|c|}
\hline & \multicolumn{3}{|c|}{ LOX/RP-1 and $\mathrm{LOX} / \mathrm{LH}_{2}{ }^{\mathrm{a}}$} & \multicolumn{3}{|c|}{$\mathrm{LOX} / \mathrm{LCH}_{4}$ and $\mathrm{LOX} / \mathrm{LH}_{2}{ }^{\mathrm{a}}$} \\
\hline & GLOW $^{b}$ & $\mathrm{SM}^{\mathrm{b}}$ & $\mathrm{EM}^{\mathrm{b}}$ & GLOW $^{b}$ & $\mathrm{SM}^{\mathrm{b}}$ & $\mathrm{EM}^{\mathrm{b}}$ \\
\hline \multicolumn{7}{|c|}{ Mass and geometry } \\
\hline $\begin{array}{l}\text { Payload bay mass, } \mathrm{t} \\
\text { Upper stage }\end{array}$ & 7.3 & 7.4 & 7.4 & 7.3 & 7.4 & 7.4 \\
\hline Structural mass, $\mathrm{t}$ & 9.8 & 7.9 & 4.9 & 9.0 & 7.2 & 4.8 \\
\hline Propellant mass, $\mathrm{t}$ & 110.8 & 86.7 & 46.6 & 100.0 & 75.4 & 44.9 \\
\hline Structural coefficient & 0.081 & 0.084 & 0.095 & 0.083 & 0.087 & 0.096 \\
\hline Diameter, m & 3.8 & 3.4 & 3.4 & 3.8 & 3.4 & 3.4 \\
\hline First stage & & & & & & \\
\hline Structural mass, $\mathrm{t}$ & 17.6 & 18.0 & 25.7 & 18.8 & 19.7 & 28.8 \\
\hline Total propellant mass, $\mathrm{t}$ & 235.4 & 277.0 & 517.9 & 232.9 & 282.3 & 519.2 \\
\hline Landing propellant mass, $\mathrm{t}$ & 8.7 & 14.0 & 46.2 & 10.6 & 17.8 & 50.5 \\
\hline Structural coefficient & 0.070 & 0.061 & 0.047 & 0.075 & 0.065 & 0.053 \\
\hline Diameter, m & 4.0 & 4.2 & 4.4 & 4.4 & 4.2 & 4.6 \\
\hline \multicolumn{7}{|c|}{ Propulsion system } \\
\hline Upper stage & & & & & & \\
\hline Number of engines & 1 & 1 & 1 & 1 & 1 & 1 \\
\hline$F_{\text {vac }}, \mathrm{kN}$ & 1186 & 946 & 538 & 1075 & 841 & 522 \\
\hline$I_{\text {sp_vac }}, \mathrm{s}$ & 450 & 448 & 445 & 450 & 448 & 446 \\
\hline$t_{b}, \mathrm{~s}$ & 413 & 403 & 378 & 411 & 394 & 376 \\
\hline$p_{c}$, bar & 115 & 100 & 75 & 105 & 115 & 80 \\
\hline $\mathrm{ROF}_{\text {engine }}$ & 6.4 & 6.7 & 7.1 & 6.4 & 6.7 & 7.0 \\
\hline Expansion ratio & 200 & 195 & 200 & 200 & 195 & 200 \\
\hline First stage & & & & & & \\
\hline $\begin{array}{l}\text { Number of engines } \\
F_{\text {vac,tot }}, \mathrm{kN}\end{array}$ & $\begin{array}{r}5 \\
5691\end{array}$ & $\begin{array}{r}5 \\
5504\end{array}$ & $\begin{array}{r}5 \\
8654\end{array}$ & $\begin{array}{r}5 \\
5454\end{array}$ & $\begin{array}{r}5 \\
5547\end{array}$ & $\begin{array}{r}5 \\
8861\end{array}$ \\
\hline$I_{\text {sp_vac }}, \mathrm{s}$ & 321 & 309 & 318 & 337 & 327 & 333 \\
\hline$I_{\mathrm{sp \_ sl}}, \mathrm{s}$ & 279 & 285 & 283 & 291 & 298 & 295 \\
\hline$t_{b}, \mathrm{~s}$ & 130 & 153 & 187 & 141 & 163 & 191 \\
\hline$p_{c}$, bar & 120 & 105 & 120 & 115 & 120 & 115 \\
\hline $\mathrm{ROF}_{\text {engine }}$ & 2.1 & 2.1 & 2.1 & 2.8 & 2.8 & 2.9 \\
\hline Expansion ratio & 30 & 15 & 25 & 30 & 20 & 25 \\
\hline Thrust/weight & 1.49 & 1.39 & 1.44 & 1.48 & 1.42 & 1.46 \\
\hline \multicolumn{7}{|c|}{ Total } \\
\hline Delta-v allocation, $\mathrm{m} / \mathrm{s}$ & $2.7 / 9.3$ & $3.2 / 8.8$ & $4.6 / 7.4$ & $2.9 / 9.1$ & $3.5 / 8.5$ & $4.7 / 7.3$ \\
\hline Length, $\mathrm{m}$ & 73.2 & 71.8 & 74.4 & 71.6 & 74.4 & 79.8 \\
\hline Total structural mass, $\mathrm{t}$ & 27.4 & 26.0 & 30.6 & 27.8 & 26.9 & 33.6 \\
\hline Expendable mass, $\mathrm{t}$ & 10.7 & 8.8 & 6.2 & 9.9 & 8.2 & 6.2 \\
\hline GLOW, $\mathrm{t}$ & 381.0 & 397.1 & 602.5 & 368.1 & 392.0 & 605.1 \\
\hline
\end{tabular}

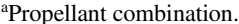

${ }^{\mathrm{b}}$ Objective function.

no longer explicitly mentioned to distinguish the different fuels from here on. Table B1 in the Appendix shows the design variables, their parameter ranges, and boundary constraints that are applied during the optimization. Apart from these restrictions, the optimization algorithm can change engine parameters, such as combustion chamber pressure, mixture ratio, throat diameter, and expansion ratio within predefined limits to find the best possible solution.

\section{Gross Lift-Off Weight}

The objective function in this section is the GLOW. Figure $\underline{3}$ shows the minimum GLOW as a function of the delta- $v$ allocation between the first and second stages. For the GTO mission, the minimum GLOW is achieved for a delta-v allocation of around $3000 \mathrm{~m} / \mathrm{s}$ for the first stage and $9000 \mathrm{~m} / \mathrm{s}$ for the upper stage. For the LEO mission, however, smaller first stages are favorable, and the optimum delta-v allocation differs between different propellant combinations.

Furthermore, the GLOW explodes for large first stages, which produce more than $4000 \mathrm{~m} / \mathrm{s}$, because more propellant is needed for the reentry burn and the landing maneuvers. Based on these results, we can derive an important conclusion: the optimum delta-v allocation that leads to the lowest GLOW depends on the mission scenarios and can vary between different propellant combinations. As the delta- $\mathrm{v}$ allocation plays an essential role during the predesign, it must be included as a parameter in the optimization routine. It cannot be chosen in advance with a default value.

The minimum GLOW of the launch vehicles shows a similar trend for both missions: the optimized $\mathrm{LH}_{2}$ launch vehicles are significantly lighter than the RP-1 and $\mathrm{LCH}_{4}$ launch vehicles. Although showing a similar trend, the $\mathrm{LCH}_{4}$ launch vehicles are around $10 \%$ lighter than the RP-1 launch vehicles, with the difference becoming greater for larger first stages. Although they are slightly heavier, the mixed-propellant launch vehicles almost reach the performance of the pure $\mathrm{LH}_{2}$ launcher. This performance is the result of the high specific impulse of the $\mathrm{LH}_{2}$ upper stage combined with the highdensity hydrocarbon fuel in the first stage. For the LEO and even more for the GTO missions, it seems that a significantly better performance is always reached, when $\mathrm{LH}_{2}$ is used in the upper stage. The difference between the actual propellants in the lower stage then makes only a smaller difference in the GLOW.

\section{Structural Mass}

The mixed-propellant launch vehicles yield the lowest overall SM for both missions, with RP-1/LH $\mathrm{LH}_{2}$ being the lightest (see Fig. 4). By benefiting from the high $I_{\mathrm{sp}}$ of $\mathrm{LH}_{2}$ and the high density of the hydrocarbons, the mixed-propellant launchers outperform launchers 


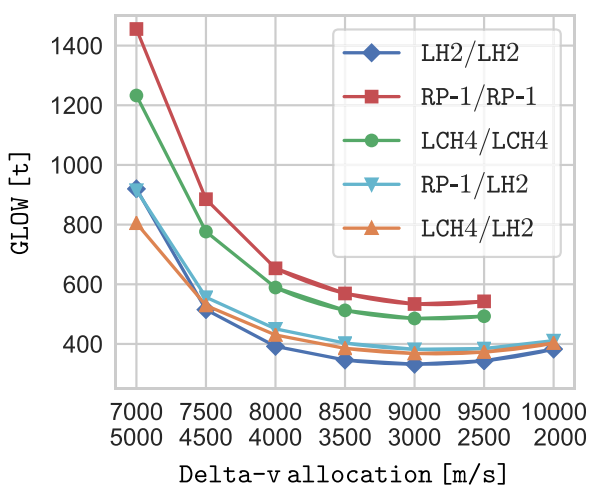

a) GTO mission

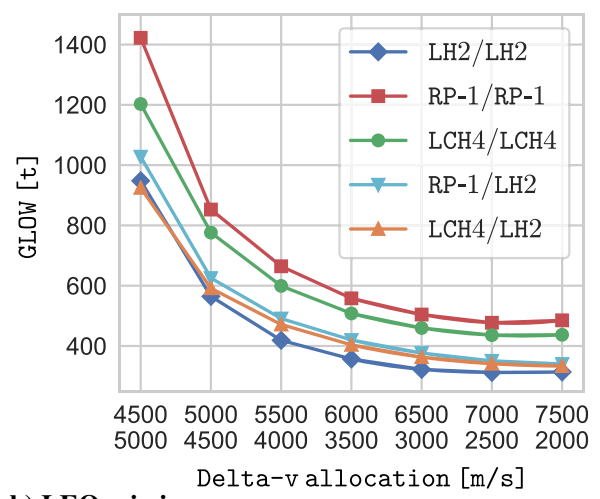

b) LEO mission

Fig. 3 Comparison of the optimized GLOW for different delta-v allocations between second stage (upper value) and first stage (lower value); the legend indicates the propellant of the first and second stages in this order.

with the same propellant combination in both stages. Regarding the single-propellant combinations, $\mathrm{LH}_{2}$ yields the highest $\mathrm{SM}$, followed by $\mathrm{LCH}_{4}$ and RP-1.

A detailed examination of the different launcher designs reveals interesting insights: comparing both mixed-propellant launchers for the GTO mission, the launch vehicle with RP-1/ $\mathrm{LH}_{2}$ has a delta-v allocation of $3200 / 8800 \mathrm{~m} / \mathrm{s}$ compared to an allocation of $3500 / 8500 \mathrm{~m} / \mathrm{s}$ for the $\mathrm{LCH}_{4} / \mathrm{LH}_{2}$ launcher. These different stage sizes lead to a slightly lower total SM of the RP-1/ $\mathrm{LH}_{2}$ launcher, whereas the $\mathrm{LCH}_{4} / \mathrm{LH}_{2}$ larger first stage of the launch vehicle features a larger portion of the SM being reused. For the LEO mission, however, the RP-1/LH $\mathrm{LH}_{2}$ launcher has both a lower total $\mathrm{SM}$ and a larger reusable first stage.

Figure 4 shows that the mass of $\mathrm{LH}_{2}$ tanks is significantly higher. This is caused by the generally larger tank sizes, but also by the necessary tank insulation. According to Castellini [9], the insulation for cryogenic $\mathrm{LH}_{2}$ tanks is $30 \%$ higher than the associated mass for a LOX-tank insulation of the same size. Finally, the propulsion system makes up around $20 \%\left(\mathrm{LH}_{2}\right)$ to $27 \%(\mathrm{RP}-1)$ of SM in the upper stage, and $23 \%\left(\mathrm{LH}_{2}\right)$ to $28 \%$ (RP-1) in the first stage.

By looking at the delta-v allocations, one can see that the upper stage contributes a larger proportion to the total delta-v for the GTO mission. Two possible explanations can be found for this: first, making a reusable first stage even larger and larger increases the total mass of the launcher because the required propellant for the reentry burn and landing maneuvers increases drastically. Hence, the upper stage needs to contribute a larger proportion for high delta-v missions, such as to a

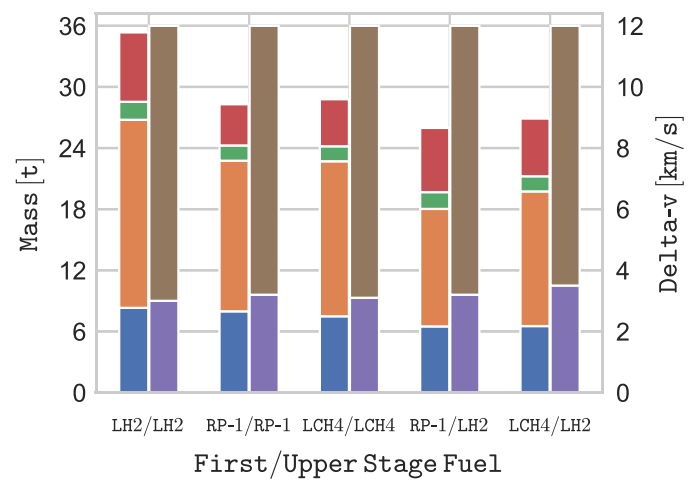

$\begin{array}{|ll|}1^{\text {st }} \text { Stage Propulsion System } & 2^{\text {nd }} \text { Stage Residual Structure } \\ 1^{\text {st }} \text { Stage Residual Structure } & 1^{\text {st }} \text { Stage Delta-v } \\ 2^{\text {nd }} \text { Stage Propulsion System } & 2^{\text {nd }} \text { Stage Delta-v }\end{array}$
GTO. Secondly, a launcher with a more powerful upper stage benefits from the high $I_{\mathrm{sp}}$ of the vacuum-optimized upper stage; thus, it can generate more delta-v.

Figure $\underline{5}$ shows the length and GLOW of the optimized launch vehicles for the GTO and the LEO missions broken down into the first stage, upper stage, and payload bay. The rocket length is not an optimization criterion, but can briefly illustrate the characteristics of the optimized launch vehicle. In general, the $\mathrm{LH}_{2}$ launch vehicles have the lowest GLOW, but they are 10-30\% longer than the $\mathrm{LCH}_{4}$ launch vehicles, which in turn are up to $8 \%$ longer than the RP-1 rockets. This effect is mainly caused by the density differences between the fuels resulting in tanks of different sizes.

The mixed-propellant RP-1/ $\mathrm{LH}_{2}$ and $\mathrm{LCH}_{4} / \mathrm{LH}_{2}$ launch vehicles seem to combine the advantages of the single-propellant rocket, yielding a relatively compact design with moderate GLOW. Comparing the mixed-propellant rockets with the $\mathrm{LH}_{2}$ design for the GTO mission, their length decreases (by up to $15 \mathrm{~m}$ ), whereas the GLOW increases only slightly (by up to $60 \mathrm{t}$ ). In contrast to the RP-1 launch vehicle, the length of the mixed-propellant rocket increases by roughly $5 \mathrm{~m}$, but their GLOW decreases by $150 \mathrm{t}$. In summary, the mixed-propellant rockets present a significant reduction in GLOW compared with the launch vehicles using only RP-1 and $\mathrm{LCH}_{4}$, and a substantial decrease in length compared to the $\mathrm{LH}_{2}$ vehicle. For the mixed-propellant rockets, $\mathrm{LCH}_{4} / \mathrm{LH}_{2}$ yields the overall lighter vehicle in terms of GLOW, whereas RP-1/LH $\mathrm{LH}_{2}$ has a slight size advantage. The LEO mission shows the same tendencies as the GTO mission, although the differences between individual propellant combinations vary slightly.

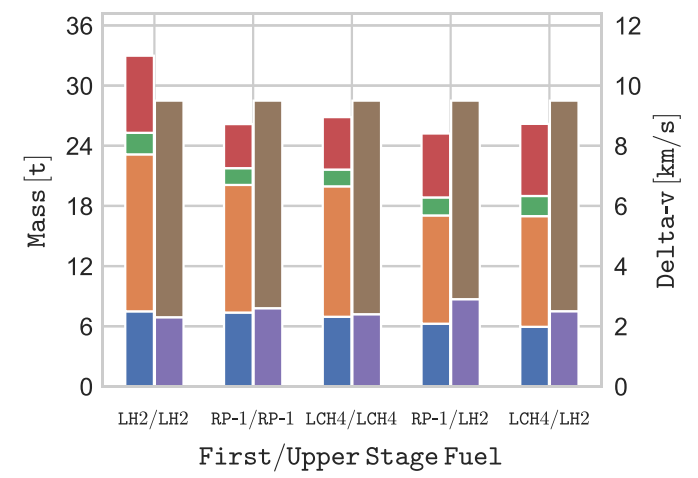

$\begin{array}{|ll|}1^{\text {st }} \text { Stage Propulsion System } & 2^{\text {nd }} \text { Stage Residual Structure } \\ 1^{\text {st }} \text { Stage Residual Structure } & 1^{\text {st }} \text { Stage Delta-v } \\ 2^{\text {nd }} \text { Stage Propulsion System } & 2^{\text {nd }} \text { Stage Delta-v }\end{array}$

b) LEO mission

Fig. 4 Delta-v allocation and optimized SM, which is broken down into the propulsion system mass (engine and thrust-vector control (TVC) system) and the residual SM of each stage. 


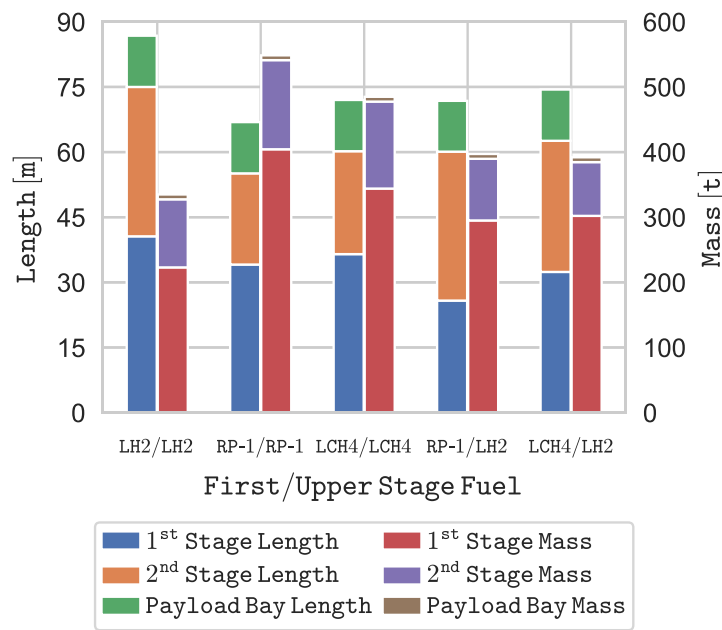

a) GTO mission

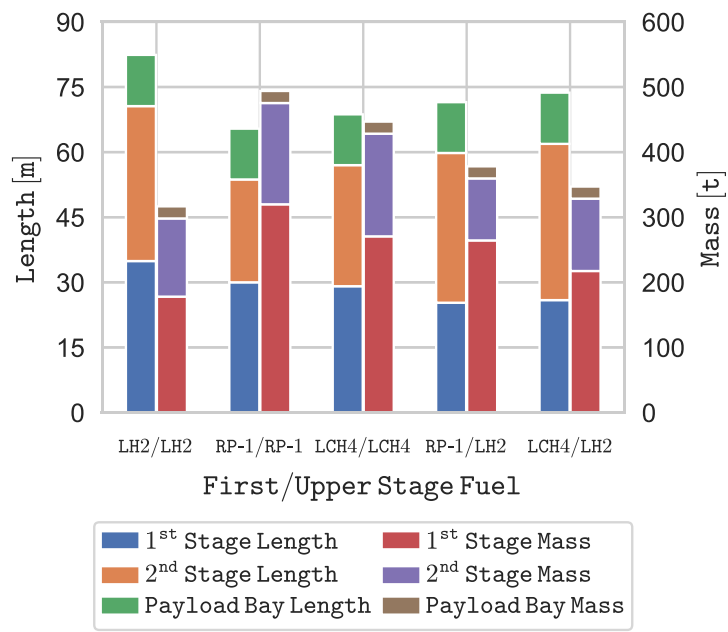

b) LEO mission

Fig. 5 Length and GLOW breakdown comparison.

\section{E. Expendable SM}

Although the previously used optimization objective does achieve the goal of reducing the total SM, representing the primary cost driver of rockets, it does not consider reusability. Therefore, we study the EM that consists of the upper-stage SM and a fraction of the firststage SM, depending on the number of reuses denoted by $n_{\text {reuses }}$. For example, if the first stage is reused 10 times, $10 \%$ of the first-stage SM is assumed to be expendable. The expendable structure mass can be written as

$$
m_{\mathrm{EM}}=m_{s, 2}+m_{s, 1} / n_{\text {reuses }}
$$

Because costs for recovery and refurbishment are not part of this study, the most cost-effective configuration may differ from the optimization program results. Additionally, fixed costs, such as costs for the factory, machines, or personnel, may shift the optimum number of reuses. These effects should be included in a follow-up study, but are difficult to quantify, and the literature lacks proper models. Here, four scenarios with 5, 10, 20, and 50 reuses of the first stage are investigated for the same five propellant combination configurations as in the previous sections. For each propellant combination and reuse case, the EM, GLOW, and first-stage delta-v are shown in Fig. 6.

For both mission scenarios and all number of first-stage reuses, the $\mathrm{LH}_{2}$ launch vehicles have the highest and the RP-1 launch vehicles the lowest EM. The mixed-propellant rockets present values near the hydrocarbon rockets for fewer reuses and are in between the hydrocarbon rockets and the $\mathrm{LH}_{2}$ launch vehicle for a larger number of reuses. This shift occurs because $\mathrm{LH}_{2}$ upper stages have greater SMs, and the influence of the upper stage on the expendable mass increases with the number of first-stage reuses.

On the other hand, the low EM of the hydrocarbon launchers results in very massive designs with a high GLOW, which might be unfavorable. When designing an actual new launch vehicle, a compromise would have to be found, which yields a low EM with still moderate GLOW. This is particularly true for the LEO mission with the lower delta-v demands. For the GTO mission, the first-stage size is limited; otherwise, the high delta-v mission requirements can no longer be met.

Increasing the number of reuses from 5 to 10,20 , or 50 yields a decrease in expendable mass of $25-28 \%, 38-44 \%$, and $47-53 \%$, respectively. Looking at the delta-v allocation of the optimized launch vehicles, a tendency to higher first stage delta-v values with an increasing number of reuses is observable. If the first stage is reused more often, it becomes profitable to build larger first stages and smaller upper stages. However, this leads to more massive rockets because the larger first stages have a much lower $I_{\mathrm{sp}}$ than the vacuum-optimized upper stages.

\section{F. Sensitivity Analyses}

By conducting sensitivity analyses, we want to broaden the conclusions of this paper to real-world applications, which certainly differ slightly from our modeling framework. Figure $\mathrm{C} 1$ in the Appendix shows the impact of changing delta-v budgets and specific impulses for a $5000 \mathrm{~kg}$ payload GTO mission. As expected, the delta-v budget and the specific impulse of the engines significantly affect the GLOW, but the overall trends remain about the same. This shows that the general insights of this study remain valid even though components or estimates are modeled in a simplified way.

Furthermore, slight deviations between the graphs, for example, the optimal delta-v distribution for $\mathrm{LCH}_{4}$ shifts depending on the $I_{\mathrm{sp}}$ (Fig. C1a), show that certain parameters must not be defined in advance with traditional values. The optimization algorithm must have the freedom to select these parameters freely, such as the delta-v distribution, to obtain the optimal rocket design.

\section{Discussion}

So far, we have compared different propellant combinations for two mission scenarios and three different optimization objectives. The results showed that the optimization objective influences the optimum propellant choice and the overall launcher design, weight, and size. This section provides a more in-depth view of chosen design variables for different optimization objectives and propellant combinations. The goal is to show how the design and engine parameter of the launcher change for different objective functions. Tables $\underline{3}$ and $\underline{4}$ compare the optimum launch vehicles for the GTO mission with a 5 t payload. For the EM, 20 reuses of the first stage are assumed. The payload bay contains the masses of the payload, the fairing, and the avionics bay. All optimized launch vehicles show a similar thrust-to-weight ratio, which seems to justify the simplistic assumption of fixed losses during the mission.

Comparing the results for the different objective functions, we can derive implications, which are similar for all propellant combinations: as already observed before, the optimum staging changes for different objective functions. If the rockets are optimized for a minimum expendable mass, the delta-v contribution of the first stage increases, leading to a more massive stage with a larger height or diameter. Consequently, the required propellant for the reentry burn and landing maneuvers grows. With this higher total stage mass, the thrust of the engines must also be increased, which simultaneously leads to higher combustion chamber pressures in the first-stage engines.

On the other hand, with larger first stages, the size of the upper stages shrinks, as their delta-v demands are much lower. The smaller size 

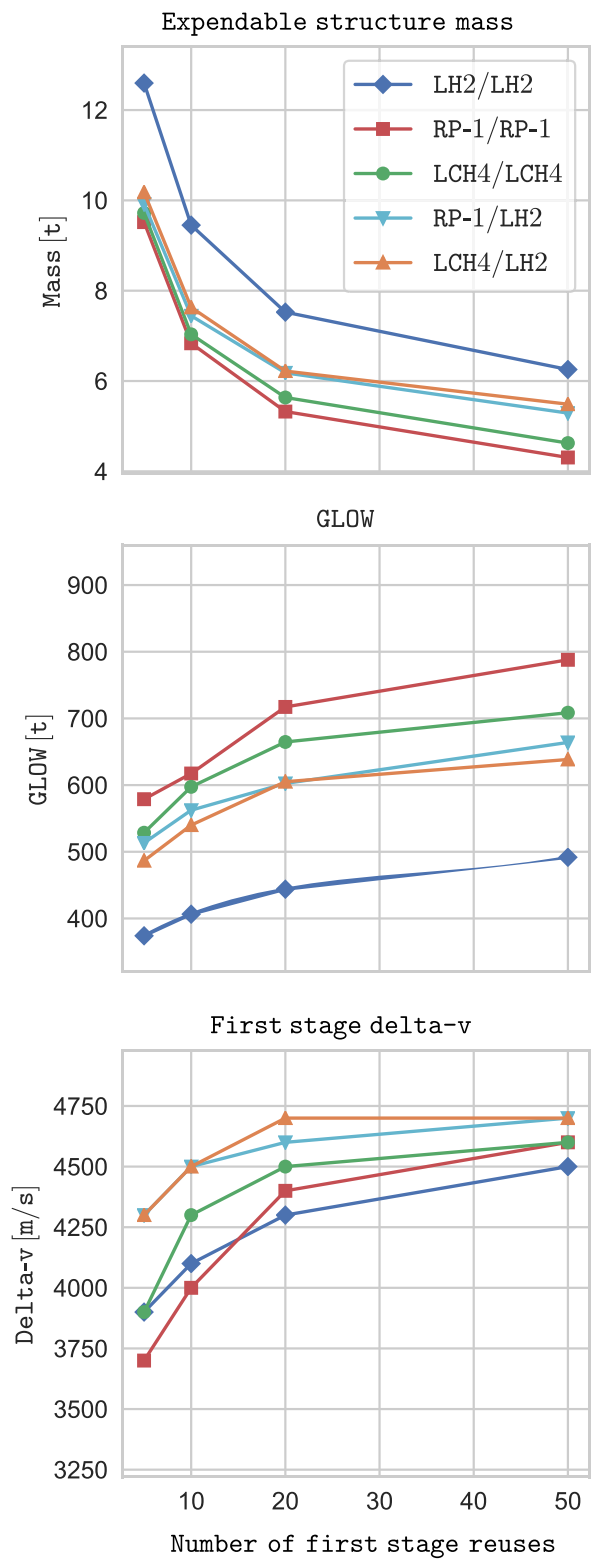

a) GTO mission
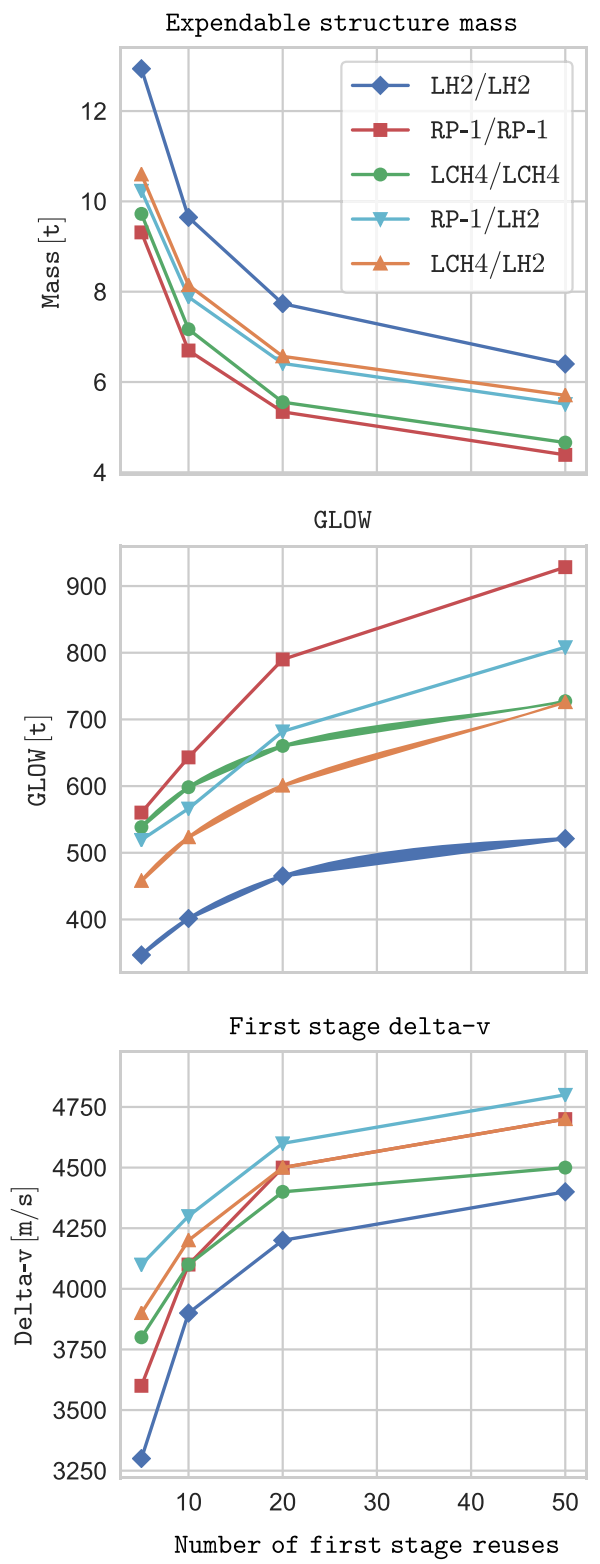

b) LEO mission

Fig. 6 Expendable SM, GLOW, and first-stage delta-v comparison.

leads to lower SMs, which is favorable, as this mass is not recoverable. Similarly, the thrust and chamber pressure of the upper-stage engine reduce with decreasing demands.

By looking at the SM-optimized launch vehicles, one can see that the optimization was successful and, in fact, leads to the lowest total SMs. For $\mathrm{LH}_{2}$, the mixture ratio is increased to benefit from the much higher density of LOX compared with $\mathrm{LH}_{2}$, thus featuring much smaller overall tank volumes and tank masses. For the hydrocarbon propellants, the optimizer chooses engines with a high sea-level $I_{\mathrm{sp}}$, achieved due to higher combustion chamber pressures or smaller expansion ratios.

Overall, the optimal number of engines in the first stage seems to be relatively small. For the implemented empirically based mass estimates, a larger number of engines apparently lead to overall higher masses or poorer engine performance, which is unfavorable. For further statements about the optimal number of engines, a more complex mass estimation, based on the masses of the individual engine components, may have to be modeled, because the currently used correlations only consider the engine mass as a function of the engine thrust.
At an engine level, the mixture ratio of the upper stage is higher than that of the first stage. In general, the $I_{\mathrm{sp}}$ of a gas-generator engine deteriorates slightly for higher mixture ratios, but the propellant tanks can be made much more compact as more high-density LOX can be stored. This effect is notably pronounced for $\mathrm{LH}_{2}$ or for an SM optimized rocket, because the tank mass is particularly relevant in this case. Of course, real technical implementation could have reasons against such high mixture ratios (e.g., cooling and combustion efficiency). Therefore, it could be that one wants to take this into account and prefer a lower mixture ratio. Nevertheless, the trend toward higher mixture ratios seems to be beneficial to the overall launcher performance.

Finally, we want to comment on the structural coefficients: as is generally known, the size of a stage strongly influences the structural index, which tends to decrease when a stage, and thus the tanks and structural components, is built larger. Based on our study, it is also clear that the structural index must not be defined in advance based on traditional values. This would prefer particular configurations and designs, because different structural coefficients emerge from the optimization, depending on the optimization goal. 


\section{Conclusions}

In this work, an optimization framework for partially reusable launch vehicles was presented. Those launch vehicles consist of two stages with a reusable first stage landing via retropropulsion similar to Falcon 9 of SpaceX. Using suitable mass estimates of all essential subsystems and a routine to calculate the needed propellant for the ascent and descent, a genetic algorithm was employed to find optimal

Table A1 Comparison of Falcon 9 with the results of the reusable launch vehicle framework

\begin{tabular}{|c|c|c|}
\hline & Falcon 9 & Optimizer \\
\hline \multicolumn{3}{|l|}{ Mass and geometry } \\
\hline Payload bay mass, $\mathrm{t}$ & 7.4 & 7.4 \\
\hline Fairing length, m & 13.2 & 10.7 \\
\hline \multicolumn{3}{|l|}{ Upper stage } \\
\hline SM, t & 4.5 & 4.9 \\
\hline Propellant mass, $\mathrm{t}$ & 111.5 & 113.7 \\
\hline Structural coefficient & 0.039 & 0.041 \\
\hline Length, $\mathrm{m}$ & 16.0 & 20.5 \\
\hline Diameter, $m$ & 3.66 & 3.66 \\
\hline \multicolumn{3}{|l|}{ First stage } \\
\hline $\mathrm{SM}, \mathrm{t}$ & 27.2 & 27.4 \\
\hline Total propellant mass, $\mathrm{t}$ & 418.7 & 436.6 \\
\hline Landing propellant mass, $\mathrm{t}$ & 25.0 & 26.6 \\
\hline Structural coefficient & 0.061 & 0.059 \\
\hline Length, $\mathrm{m}$ & 40.9 & 48.3 \\
\hline Diameter, m & 3.66 & 3.66 \\
\hline \multirow{2}{*}{\multicolumn{3}{|c|}{$\begin{array}{l}\text { Propulsion system } \\
\text { Upper stage }\end{array}$}} \\
\hline & & \\
\hline Number of engines & 1 & 1 \\
\hline$F_{\mathrm{vac}}, \mathrm{kN}$ & 981 & 1074 \\
\hline$I_{\mathrm{sp} \_ \text {vac }}, \mathrm{s}$ & 348 & 351 \\
\hline$t_{b}, \mathrm{~s}$ & 397 & 364 \\
\hline \multicolumn{3}{|l|}{ First stage } \\
\hline Number of engines & 9 & 9 \\
\hline$F_{\text {vac,tot }}, \mathrm{kN}$ & 8227 & 8536 \\
\hline$F_{\mathrm{sl}, \mathrm{tot}}, \mathrm{kN}$ & 7607 & 7770 \\
\hline$I_{\text {sp_vac }}, \mathrm{s}$ & 312 & 310 \\
\hline$I_{\mathrm{sp} \_\mathrm{sl}}, \mathrm{s}$ & 283 & 282 \\
\hline$t_{b}, \mathrm{~s}$ & 162 & 156 \\
\hline \multicolumn{3}{|l|}{ Total } \\
\hline GLOW, t & 569.3 & 589.9 \\
\hline Length, m & 70.1 & 80.6 \\
\hline \multicolumn{3}{|l|}{ Delta-v } \\
\hline Upper stage, $\mathrm{km} / \mathrm{s}$ & 8.5 & 8.5 \\
\hline First stage, km/s & 3.5 & 3.5 \\
\hline Total, km/s & 12.0 & 12.0 \\
\hline
\end{tabular}

designs for different objective functions and propellant combinations: $\mathrm{LOX} / \mathrm{LH}_{2}$, LOX/RP-1, and $\mathrm{LOX} / \mathrm{LCH}_{4}$. Concerning propulsion, gas-generator cycle liquid rocket engines in both stages were assumed. Apart from this, the optimization algorithm can change engine parameters, such as combustion chamber pressure, mixture ratio, throat diameter, and expansion ratio, within predefined limits to find the best possible solution.

Not surprisingly, the results show that the question of which design and which propellant combination is the most suitable depends strongly on the assumed objective function. If one optimizes according to GLOW, the launch vehicles that use $\mathrm{LOX} / \mathrm{LH}_{2}$ in both stages perform best. If one optimizes according to $\mathrm{SM}$, launch vehicles with LOX/RP-1 or $\mathrm{LOX} / \mathrm{LCH}_{4}$ in the first stage and $\mathrm{LOX} / \mathrm{LH}_{2}$ in the second stage are optimal. On the other hand, if one optimizes according to an EM for five reuses and more, the configurations that only use LOX/RP-1 or LOX/ $\mathrm{LCH}_{4}$ give the best results. Furthermore, the optimal engine design parameters also change, depending on the chosen objective function.

The present work can be improved in many directions: first, different propellant tank designs like using a common bulkhead should be included, and the tank design should be further optimized (see [23]). Second, the simplified modeling of aerodynamics and losses should be upgraded. Third, other engine power cycles (e.g., staged combustion or expander, or additional solid or liquid boosters) could be investigated. Another idea is to impose the same combustion chamber for the first and second stages, as this would lower the development costs. It would be exciting to study when and how the coupling with a trajectory optimization program changes the results on a global level. Finally, a toss-back trajectory could be an interesting case study, as it adds another dimension to the optimization loop: the staging velocity and the velocity slope at separation directly impact the necessary propellant for the following boost-back burn.

To investigate the most relevant goal of cost reduction, appropriate cost estimates must be integrated. Using appropriate cost estimates instead of mass-based objective functions would result in the launcher design that yields the lowest overall cost for a given payload and mission.

\section{Appendix A: Comparison with Falcon 9}

Table A1 compares the real Falcon 9 with the results from the resuable launch vehicle framework. Both rockets and their propulsion systems are quite similar, differing mostly in the length of the rocket due to our simplified propellant tank models.

\section{Appendix B: Rocket Parameters: Boundary Values and Constraints}

Table B1 in the Appendix shows the design variables, their parameter ranges, and boundary constraints that are applied during the optimization.

Table B1 Boundary values and constraints for the optimization program

\begin{tabular}{lcc}
\hline \hline Parameter & Boundary values (first stage) & Boundary values (upper stage) \\
\hline Stage radius, $\mathrm{m}$ & $1.5-4$ & $1.5-4$ \\
Minimum $0.75 r_{1 \text { st stage }}$ & & \\
Maximum $1.00 r_{1 \text { st stage }}$ & & \\
\hline Nozzle throat diameter, $\mathrm{m}$ & $0.1-1$ & $0.1-1$ \\
Combustion chamber pressure, bar & $50-200$ & $20-200$ \\
Nozzle area expansion ratio & $10-90$ & $80-200$ \\
Mixture ratio & LOX/LH 2 & $4.0-7.9$ \\
& LOX/RP-1 & $1.5-3.5$ \\
& LOX/LCH & $2.0-4.0$ \\
\hline Minimum number of engines & 5 & 1 \\
Maximum number of engines & 15 & 1 \\
Minimum acceleration & $1.3 \mathrm{~g}$ & $0.95 \mathrm{~g}$ \\
Maximum length/diameter & & 20 \\
\hline \hline
\end{tabular}



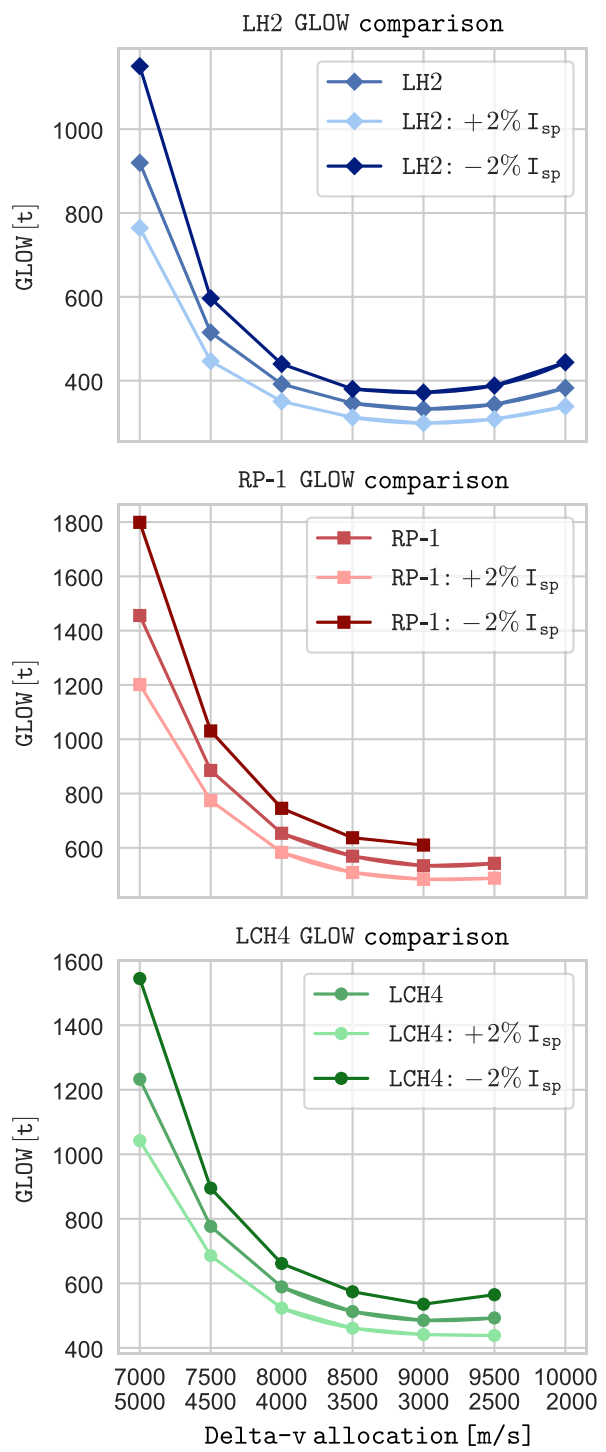

a) Specific impulse
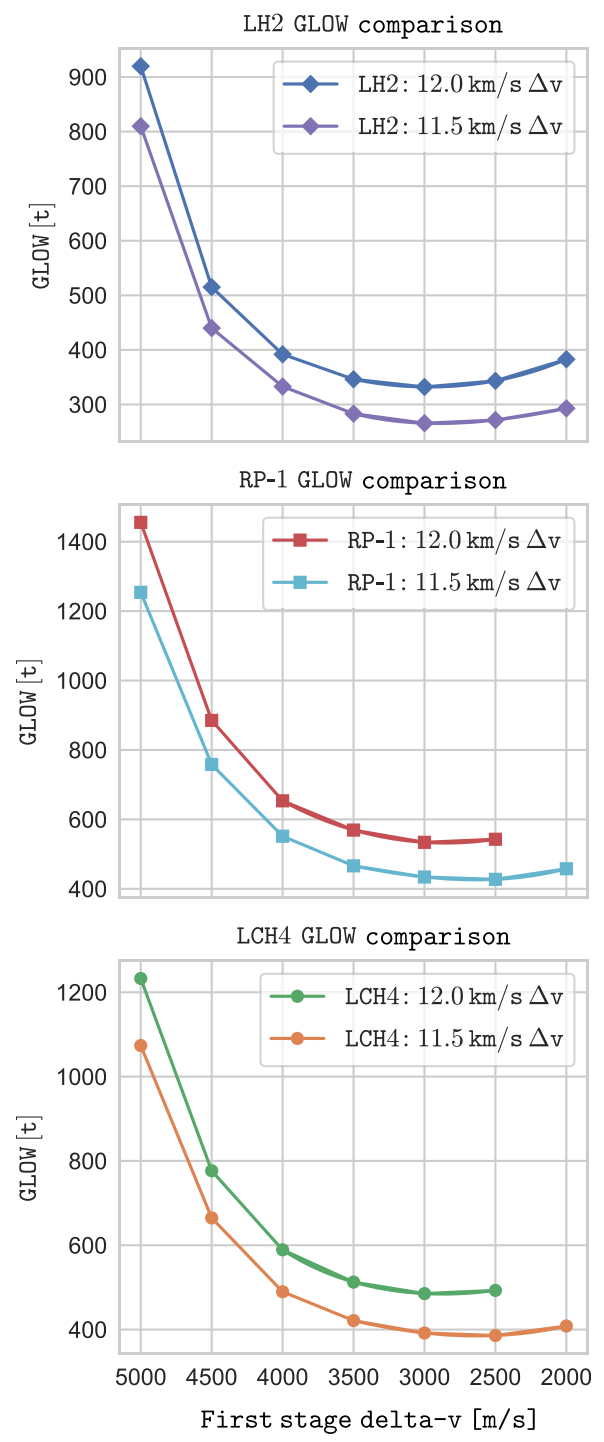

b) Delta-v budget

Fig. C1 Sensitivity analyses.

\section{Appendix C: Sensitivity Analyses}

Figure $\mathrm{C} 1$ shows the impact of changing delta-v budgets and specific impulses for a $5000 \mathrm{~kg}$ payload GTO mission. As expected, the delta-v budget and the specific impulse of the engines significantly affect the GLOW, but the overall trends remain about the same.

\section{References}

[1] Blair, J. C., Ryan, R. S., Schutzenhofer, L. A., Signal, A., and Humphries, W. R., "Launch Vehicle Design Process: Characterization, Technical Integration, and Lessons Learned," NASA TP 210992, 2001.

[2] Braun, R., Moore, A., and Kroo, I., "Use of the Collaborative Optimization Architecture for Launch Vehicle Design," 6th Symposium on Multidisciplinary Analysis and Optimization, AIAA Paper 1996-4018, Sept. 1996.

https://doi.org/10.2514/6.1996-4018

[3] Rowell, L., Olds, J., and Unal, R., "Recent Experiences in Multidisciplinary Conceptual Design Optimization for Launch Vehicles," 6th Symposium on Multidisciplinary Analysis and Optimization, AIAA Paper 1996-4050, Sept. 1996. https://doi.org/10.2514/6.1996-4050

[4] Koelle, D., "The Cost-Optimal Size of Future Reusable Launch Vehicles," Acta Astronautica, Vol. 47, Nos. 2-9, 2000, pp. 205-213. https://doi.org/10.1016/S0094-5765(00)00060-6

[5] Duranté, N., Dufour, A., Pain, V., Baudrillard, G., and Schoenauer, M., "Multi-Disciplinary Analysis and Optimisation Approach for the
Design of Expendable Launchers," 10th AIAA/ISSMO Multidisciplinary Analysis and Optimization Conference, AIAA Paper 2004-4441, Aug. 2004. https://doi.org/10.2514/6.2004-4441

[6] Bayley, D., Hartfield, R., Burkhalter, J., and Jenkins, R., "Design Optimization of a Space Launch Vehicle Using a Genetic Algorithm," 48th AIAA/ASME/ASCE/AHS/ASC Structures, Structural Dynamics, and Materials Conference, AIAA Paper 2007-1863, April 2007. https://doi.org/10.2514/6.2007-1863

[7] Briggs, G., Ray, T., and Milthorpe, J., "Evolutionary Algorithm Use in Optimisation of a Launch Vehicle Stack Model," 45th AIAA Aerospace Sciences Meeting and Exhibit, AIAA Paper 2007-0364, Jan. 2007. https://doi.org/10.2514/6.2007-364

[8] Castellini, F., Lavagna, M., Riccardi, A., and Bueskens, C., "Multidisciplinary Design Optimization Models and Algorithms for Space Launch Vehicles," 13th AIAA/ISSMO Multidisciplinary Analysis Optimization Conference, AIAA Paper 2010-9086, Sept. 2010. https://doi.org/10.2514/6.2010-9086

[9] Castellini, F., "Multidisciplinary Design Optimization for Expendable Launch Vehicles," Ph.D. Thesis, Polytechnic Univ. of Milan, Milan, 2012.

[10] Patureau De Mirand, A., Bahu, J.-M., and Louaas, E., "Ariane Next, a Vision for a Reusable Cost Efficient European Rocket," Proceedings of the 8th European Conference for Aeronautics and Space Sciences (EUCASS), Madrid, Spain, 2019, p. 9. https://doi.org/10.13009/EUCASS2019-949

[11] Ukai, S., Sakaki, K., Ishikawa, Y., Sakaguchi, H., and Ishihara, S., "Component Tests of a LOX/Methane Full-Expander Cycle Rocket 
Engine: Injector and Regeneratively Cooled Combustion Chamber," Proceedings of the 8th European Conference for Aeronautics and Space Sciences (EUCASS), Madrid, Spain, 2019, p. 9.

[12] Kajon, D., Liuzzi, D., Boffa, C., Rudnykh, M., Drigo, D., Arione, L., Ierardo, N., and Sirbi, A., "Development of the Liquid Oxygen and Methane M10 Rocket Engine for the Vega-E Upper Stage," Proceedings of the 8th European Conference for Aeronautics and Space Sciences (EUCASS), Madrid, Spain, 2019, p. 8. https://doi.org/10.13009/EUCASS2019-315

[13] Traudt, T., Deeken, J. C., Oschwald, M., and Schlechtriem, S., "Liquid Upper Stage Demonstrator Engine (LUMEN): Status of the Project," 70th International Astronautical Congress (IAC), Washington, D.C., 2019, p. 8.

[14] Soller, S., Maeding, C., Kniesner, B., Preuss, A., Rackemann, N., and Blasi, R., "Characterisation of a LOX-LCH4 Gas Generator," Space Propulsion Conference, Cologne, Germany, 2014, p. 10.

[15] Börner, M., Manfletti, C., Hardi, J., Suslov, D., Kroupa, G., and Oschwald, M., "Laser Ignition of a Multi-Injector LOX/Methane Combustor," CEAS Space Journal, Vol. 10, No. 2, 2018, pp. 273-286. https://doi.org/10.1007/s12567-018-0196-6

[16] Haemisch, J., Suslov, D., and Oschwald, M., "Experimental Study of Methane Heat Transfer Deterioration in a Subscale Combustion Chamber," Journal of Propulsion and Power, Vol. 35, No. 4, 2019, pp. 819-826. https://doi.org/10.2514/1.B37394

[17] Waxenegger-Wilfing, G., Dresia, K., Deeken, J. C., and Oschwald, M., "Heat Transfer Prediction for Methane in Regenerative Cooling Channels with Neural Networks," Journal of Thermophysics and Heat Transfer, Vol. 34, No. 2, 2020, pp. 347-357. https://doi.org/10.2514/1.T5865

[18] Balesdent, M., "Multidisciplinary Design Optimization of Launch Vehicles," Ph.D. Thesis, École Centrale de Nantes, Nantes, France, 2012.

[19] Wertz, J. R., "Responsive Launch Vehicle Cost Model," Space Propulsion 2004, Los Angeles, 2004, p. 13.

[20] Koelle, D. E., Handbook of Cost Engineering for Space Transportation Systems with TRANSCOST 8.2: Statistical-Analytical Model for Cost Estimation and Economical Optimization of Launch Vehicles, TCS-TR, TransCostSystems, Ottobrunn, 2013, pp. 1-264.

[21] Balesdent, M., Brevault, L., Price, N. B., Defoort, S., Le Riche, R., Kim, N.-H., Haftka, R. T., and Bérend, N., "Advanced Space Vehicle Design Taking into Account Multidisciplinary Couplings and Mixed Epistemic/ Aleatory Uncertainties," Space Engineering, edited by G. Fasano, and J. D. Pintér, Vol. 114, Springer, Cham, Switzerland, 2016, pp. 1-48. https://doi.org/10.1007/978-3-319-41508-6_1

[22] Briese, L. E., Acquatella, B. P., and Schnepper, K., "Multidisciplinary Modeling and Simulation Framework for Launch Vehicle System Dynamics and Control," Acta Astronautica, Vol. 170, May 2020, pp. 652-664. https://doi.org/10.1016/j.actaastro.2019.08.022

[23] Vietze, M., Mundt, C., and Weiland, S., "Cryogenic Launcher Stage Optimization Toolbox," Journal of Spacecraft and Rockets, Vol. 55, No. 2, 2018, pp. 257-265.

https://doi.org/10.2514/1.A33924

[24] Stappert, S., Wilken, J., Bussler, L., Sippel, M., Karl, S., Klevanski, J., Hantz, C., Briese, L. E., and Schnepper, K., "European Next Reusable Ariane (ENTRAIN): A Multidisciplinary Study on a VTVL and a VTHL Booster Stage," Proceedings of the 70th International Astronautical Congress 2019 (IAC), Washington, D.C., 2019, p. 17.
[25] Moroz, L., Burlaka, M., Barannik, V., Kochurov, R., and Maksiuta, D., "Liquid Rocket Propulsion Launcher Design System to Train AxSTREAM.AI. Reusability Aspects," 8th European Conference for Aeronautics and Space Science (EUCASS), Madrid, Spain, 2019, p. 11.

[26] Brevault, L., Balesdent, M., and Hebbal, A., "Multi-Objective Multidisciplinary Design Optimization Approach for Partially Reusable Launch Vehicle Design," Journal of Spacecraft and Rockets, Vol. 57, No. 2, 2020, pp. 373-390. https://doi.org/10.2514/1.A34601

[27] Christall, S., "Linking of Liquid Bipropellant Rocket Engine Design Methodology with Launch Vehicle Optimization," M.S. Thesis, Univ. of Würzburg, Würzburg, Germany, 2017.

[28] Jentzsch, S., "Optimization of a Reusable Launch Vehicle Using Genetic Algorithms," M.S. Thesis, RWTH Aachen, Aachen, Germany, 2020.

[29] Waxenegger-Wilfing, G., Dos Santos Hahn, R. H., and Deeken, J. C., "Studies on Electric Pump-Fed Liquid Rocket Engines for MicroLauncher," Proceedings of the Space Propulsion 2018, Seville, Spain, 2018, p. 8.

[30] Stappert, S., Wilken, J., Sippel, M., and Dumont, E., "Assessment of a European Reusable VTVL Booster Stage," Proceedings of the Space Propulsion 2018, Seville, Spain, 2018, p. 12.

[31] McBride, B., and Gordon, S., "Computer Program for Calculation of Complex Chemical Equilibrium Compositions and Applications, II. Users Manual and Program Description," NASA Reference Publ. 1311, 1996.

[32] Coley, D. A., An Introduction to Genetic Algorithms for Scientists and Engineers, World Scientific, Singapore, 1999, pp. 1-244. https://doi.org/10.1142/3904

[33] Bäck, T., Evolutionary Algorithms in Theory and Practice: Evolution Strategies, Evolutionary Programming, Genetic Algorithms, Oxford Univ. Press, New York, 1996, pp. 1-328.

[34] Son, M., Ko, S., and Koo, J., "Genetic Algorithm to Optimize the Design of Main Combustor and Gas Generator in Liquid Rocket Engines," Journal of Thermal Science, Vol. 23, No. 3, 2014, pp. 259-268. https://doi.org/10.1007/s11630-014-0704-8

[35] Marcus, M. L., and Sedwick, R. J., "Low Earth Orbit Debris Removal Technology Assessment Using Genetic Algorithms," Journal of Spacecraft and Rockets, Vol. 54, No. 5, 2017, pp. 1110-1126. https://doi.org/10.2514/1.A33671

[36] Castellini, F., and Lavagna, M. R., "Comparative Analysis of Global Techniques for Performance and Design Optimization of Launchers," Journal of Spacecraft and Rockets, Vol. 49, No. 2, 2012, pp. 274-285. https://doi.org/10.2514/1.51749

[37] Pelamatti, J., Brevault, L., Balesdent, M., Talbi, E.-G., and Guerin, Y., "Bayesian Optimization of Variable-Size Design Space Problems," Optimization and Engineering, 2020, pp. 387-447. https://doi.org/10.1007/s11081-020-09520-z

[38] Fortin, F.-A., De Rainville, F.-M., Gardner, M.-A., Parizeau, M., and Gagné, C., "DEAP: Evolutionary Algorithms Made Easy," Journal of Machine Learning Research, Vol. 13, No. 1, 2012, pp. 2171-2175.

[39] Ley, W., Wittmann, K., and Hallmann, W. (eds.), Handbuch der Raumfahrttechnik, Hanser, Munich, 2019, pp. 66-139.

C. Bonnal

Associate Editor 